\title{
The Adventure and Beauty of Chemistry ${ }^{1}$
}

Scientists need to urgently recover the beauty of science as well as preserve its quality.

Most of them are more concerned about indicators and numerical indexes than about the quality of the science they have been practicing itself.

The quality of a scientific article has currently been measured much more by the impact of the journal it has been published in than by its contribution to knowledge.

Of course journals should be ranked and accordingly some of them are better than others. But, even in the journals considered the best, one can sometimes find somewhat "reheated" articles.

Creativity has given place to technique in which what matters is the equipment, even if the measurements taken could be done in simpler and more affordable machines. This has happened in all knowledge fields considered hard, such as Chemistry and Physics.

Getting measurements and tabulating them can not be considered science. But, unfortunately, this has been the prevalent practice among a great number of scientists to whom the quantity of papers is more important than the quality of the science they practice.

It is rare nowadays to have lecturers highlighting their own work, but we frequently see them proudly emphasizing the journal in which it has been published.

Many readers of this editorial may think that its author has forgotten to mention that article quality can be measured by the number of citations it has received.

It is true that the citation number is an excellent quality indicator. However, even that has come to be, in many cases, a fake indicator because of the existence of "citation clubs".

To make things still worse, we have seen editors suggesting the citation of articles published in their journals in order to improve their impact factor, not to mention the unnecessary self-citation made by many authors.
An important scientific journal is one that is much read and appreciated by its readers. If its indicators are good, that is better. What is unacceptable is editors looking for indicators, forgetting the quality of what is being published.

In case certain dogmas prevail, young people will start avoiding science more and more and thus such activity will be restricted to "older people" until they do not exist anymore, because the number of journals is growing in a greater pace than the number of young people that are opting for a scientific career.

Beauty, Science and Arts are Siamese sisters. No doubt, the more the beauty of an article, the better and more qualified its author or authors, for modern science results most of the time from team work.

To recover the beauty of science and to prevent it being outsourced is the duty of every scientist and, mainly, of scientific journal editors. The latter are in charge of insuring the practice of a good science.

Science is a great adventure, which should be experienced in its fullness. And as any adventure, it is beautiful for those who give themselves to it body and soul.

Chemists, as sorcerers' and alchemists' heirs, have a vocation for adventure. That is why it is the duty of all advisers to inculcate in their students the spirit of adventure and to show them that CHEMISTRY has as much beauty as any work of art, as long as it is practiced with creativity, quality and, most of all, with full commitment.

Angelo C. Pinto

JBCS Editor

\section{References}

1. Laszlo, P. The great adventure of chemistry. Portuguese Chemical Society, Bulletin 2002, 85, 23. Available at: http://www.spq.pt/boletim/docs/BoletimSPQ_085_023_07.pdf 